\title{
Accessibility and uncertainty: An empirical analysis of option value in transport
}

\author{
Anders Bondemark \\ anders.bondemark@vti.se \\ Fredrik Kopsch \\ Lund University \\ fredrik.kopsch@lth.lu.se
}

VTI-The Swedish National Road and Transport Research Institute and Lund University

\author{
Erik Johansson \\ WSP Advisory, WSP Sverige AB \\ erik.a.johansson@wsp.com
}

Abstract: Are there option values for transport services? A few studies have tried to answer this question through various stated preference methods, but we do not know much about its magnitude in different contexts. In this paper, we summarize the theory on option value, present previous empirical work concerning transport, and discuss its links to accessibility. Accessibility can be seen as the end product of the transport system, and the argument we pursue is that option value is a component of accessibility. Therefore, estimations of the option value ought to be connected to the marginal accessibility change of an optional transport mode. The concept of substitutability has the potential to meet this criterion. It is the degree to which an alternative trip can replace an initially preferred trip, or, put differently, how accessibility at a location is composed. We conduct an empirical application to test whether the variation in housing transaction prices is associated with substitutability. We find that housing prices are higher where the accessibility is built up by several transport modes, given any level of total accessibility. We interpret this as households, on average, are willing to pay a risk premium to keep optional transport modes available.

\section{Article history:}

Received: April 29, 2020

Received in revised form: August 27, 2020

Accepted: December 6, 2020

Available online: April 14, 2021

\section{Introduction}

Transport infrastructure and other public services rely to various degrees on government coordination and subsidies. Arguments for subsidization of public transport operations typically include economies of scale and as a second-best policy to discourage car use (Parry \& Small, 2009). To get a picture of the reasonable subsidy level, transport appraisals aim to include all internal and external effects of an action. In line with this, Boardman, Greenberg, Vining, and Weimer (2014) state that evaluations of individual benefits should also be corrected for the presence of uncertainty, or so-called option values (OV). Weisbrod (1964), who coined the term, argued that there might be a value of particular services (e.g., transport modes) for those who do not regularly use them but rely on them due to uncertainty about the future. The literature suggests that this uncertainty is not fully captured in standard appraisal tools.

Cicchetti and Myrick Freeman (1971) advanced the microeconomic foundations of OV, and it

Copyright 2021 Anders Bondemark, Erik Johansson \& Fredrik Kopsch

http://dx.doi.org/10.5198/jtlu.2021.1783

ISSN: 1938-7849 | Licensed under the Creative Commons Attribution - Noncommercial License 4.0

The Journal of Transport and Land Use is the official journal of the World Society for Transport and Land Use (WSTLUR) and is published and sponsored by the University of Minnesota Center for Transportation Studies. 
was early on seen as relevant for environmental and natural resource economics (Barbier, 1994; Krutilla, 1967). Still, in transport economics, it has not attracted much attention (van Wee, 2016). That said, van Wee (2016) argued that it is an avenue for accessibility research, and Stanley and Levinson (2016) highlighted it as a possible path to bridge the benefit/funding gap within public transport.

Various stated preference approaches have been employed to analyze OV in transport (Laird, Guers, \& Nash, 2009). We see that there are two limitations in previous literature. First, there is a risk that researchers use ad-hoc taxonomies about the total economic value of a policy (Carson, Flores, \& Mitchell, 2001), and there is no simple way to separate the OV from the consumer surplus (Boardman et al., 2014). Secondly, previous studies commonly analyze single transport services without addressing their relative accessibility impact (only Chang, 2010; Chang, Cho, Lee, Kim, \& Yun, 2012, go a bit further and study the headway of services). With this approach, it becomes difficult to relate the results to transport and land-use systems (van Wee, 2016). In other words, the level of service of a specific transport mode does not tell you much about the accessibility of a particular place, and it is therefore impossible to generalize the estimated OV beyond the specific service that is studied.

The principal aim of this paper is to address the latter limitation. We depart from van Wee's (2016) idea that the OV is related to accessibility and connect this to the concept of substitutability (van Wee, van Cranenburgh, \& Maat, 2019). Substitutability originates from the concept of substitute goods and services, which suggest that an increased price of good $\mathrm{x}$ leads to increased consumption of good $\mathrm{y}$, given that $\mathrm{x}$ and $\mathrm{y}$ are substitutes. We advance the idea that a measure of substitutability would represent the value of having substitute transport modes in this case. In other words, the substitutability measure is an indicator of the total OV at a specific location.

In this study, we are using a hedonic model to analyze real estate transaction prices as a function of accessibility (measured as logsum), substitutability, and other attributes that explain the value of real estate. Previous literature on hedonic pricing concludes that accessibility is positively associated with real estate values, i.e., location matters (Bohman \& Nilsson, 2016; Debrezion, Pels, \& Rietveld, 2007; Eliasson, Kopsch, Mandell, \& Wilhelmsson, 2020; Mohammad, Graham, Melo, \& Anderson, 2013). Our results suggest that both accessibility and substitutability are positively associated with real estate prices, i.e., having substitute transport modes seems to be a positively valued attribute of real estate.

The rest of the paper is outlined as follows. Section 2 introduces the OV, including its theoretical background and previous empirical work. Section 3 introduces accessibility and substitutability; we present how it can be used to improve the literature on OV. In section 4, we outline the data and the hedonic pricing model. Section 5 presents and interprets the results, and section 6 concludes the paper and give policy recommendations.

\section{Option value}

\subsection{Theoretical origins}

In his seminal paper, Weisbrod (1964) pointed out three criteria for the OV to be relevant (see also Cicchetti \& Myrick Freeman, 1971, for an outline of these criteria). First, the demand for a commodity is infrequent and uncertain. Secondly, should the production of the commodity be curtailed, it would be very costly or impossible to re-establish it. Thirdly, the commodity is characterized by incomplete excludability and storability. Critics claimed that option valuation would double count the consumer surplus (Long, 1967), but Lindsay (1969) refuted this criticism and emphasized that uncertainty is the key to understand OV. In this paper, the OV is defined as the value of the "option of consuming [a] good at some point in the future, even if [the individual] may never actually take up that option" (Laird 
et al., 2009, p. 174).

The kind of uncertainty that we are referring to is unmeasurable uncertainty, as emphasized by Knight (1921). Uncertainty must not be confused with risk, which assumes a known set of turnouts and a known probability space, making it possible to measure expected payoff. In a world of (unmeasurable) uncertainty, an individual may seek to avoid potentially harmful consequences from rare events. Thus, the principle of OV derives from the idea that people cannot predict and protect themselves from rare events, but need to adjust to their existence (Taleb, 2010).

A driving rationale behind accounting for a potential $\mathrm{OV}$ is to include it in appraisals, which aim is to sum all effects of a project and fully evaluate them. Presuming values can be measured objectively, a cost-benefit analysis (CBA) seeks to include the total economic value (TEV), which consists of all values that arise as a consequence of a measure. In recent literature, however, there is inconsistency regarding the division of TEV (Chang et al., 2017). In some cases, the OV is a separate category (Chang, Jung, Ross, \& Kim, 2012; Laird et al., 2009), while others categorize it as a use-value (Geurs, Haaijer, \& van Wee, 2006), or as a non-use value (Humphreys \& Fowkes, 2006).

A more straightforward taxonomy to sort the TEV mentally is to differentiate the components between "active" and "passive" use. Carson et al. (2001) suggested a definition of passive-use as the portion of the TEV left after measuring observed market behavior. The passive-use values can, for example, be OV and existence value (Boardman et al., 2014). Carson et al. (2001) argued that definitions based on particular research purposes might lead to ad-hoc taxonomies and that this is one possible reason as to why there are inconsistencies in the empirical literature.

\subsection{Empirical overview}

Up until 2009, five published studies had been trying to capture all or parts of the TEV of bus or rail services (Laird et al., 2009). The literature review by Laird et al. (2009) concluded that option and non-use values are context-dependent. Further, the highest valued services in terms of the option and non-use values seem to be high-quality rail, while the lowest valued services are low-quality buses.

Since 2009, an additional six papers have been published (Chang, 2010; Chang et al., 2012; Chang et al. 2017; Johnson, Jackson, \& Nash, 2013; Laird, Johnson, Corso, \& Tucta, 2013; Wallis \& Wignall, 2012). Wallis and Wignall (2012) and Laird et al. (2013) are, to our knowledge, not peer-reviewed. What unifies all previous papers, both pre- and post-2009, is the use of stated preference methods. However, the recent six papers differ methodologically in the way that they disaggregated the stated values. In, for example, Chang (2010) and Chang et al. (2012), the researchers were categorizing the respondents as, for instance, users or optional users based on their travel habits. Contrastingly, Johnson et al. (2013) and Laird et al. (2013) asked the respondents to assign the proportion of their answers that belonged to the different value categories. 
Table 1. A summary of transport studies on the option values (OV), non-use values (NUV) and use values (UV) after 2009

\begin{tabular}{llllll}
\hline & Country & \multicolumn{1}{c}{$\begin{array}{c}\text { Mode of } \\
\text { transport }\end{array}$} & $\begin{array}{c}\text { Geographical } \\
\text { context }\end{array}$ & \multicolumn{1}{c}{ Attribute } & Values measured \\
\hline Chang (2010) & South Korea & Rail & Intercity & $\begin{array}{l}\text { Headway, service } \\
\text { removal }\end{array}$ & OV and NUV \\
$\begin{array}{l}\text { Chang et al. } \\
\text { (2012) }\end{array}$ & South Korea & Bus & $\begin{array}{l}\text { Urban, metro- } \\
\text { politan, intercity }\end{array}$ & $\begin{array}{l}\text { Headway, service } \\
\text { removal }\end{array}$ & OV and NUV \\
$\begin{array}{l}\text { Wallis and } \\
\text { Wignall (2012) }\end{array}$ & New Zealand & Bus and Train & $\begin{array}{l}\text { Regional, small } \\
\text { communities }\end{array}$ & $\begin{array}{l}\text { Service removal, } \\
\text { service introduction } \\
\text { from a low level }\end{array}$ & OV and NUV \\
$\begin{array}{l}\text { Johnson et al. } \\
\text { (2013) }\end{array}$ & United Kingdom & Rail & Regional & $\begin{array}{l}\text { Public transport head- } \\
\text { way, post office service, }\end{array}$ & OV and NUV \\
$\begin{array}{l}\text { Laird et al. } \\
\text { (2013) }\end{array}$ & United Kingdom & Buses & Urban & $\begin{array}{l}\text { Service removal, head- } \\
\text { way, council tax }\end{array}$ & OV and NUV \\
$\begin{array}{l}\text { Chang et al. } \\
\text { (2017) }\end{array}$ & South Korea & Expressways & Regional & Road taxes & UV and NUV \\
\hline
\end{tabular}

Table 1 summarizes the papers concerning their context, analyzed attribute and the values of study. Chang (2010) and Chang et al. (2012) applied a dichotomous choice model to rail and bus services in South Korea, respectively. These studies stand out from the rest because they included each respondent's intended trip distance in the analysis, besides the common attributes of changes in headway or service removal. The argument, according to Chang (2010), is that people assign higher OVs for longer trips than for shorter trips, everything else being equal. The results in Chang (2010) were based on a sample of 242 individuals for the estimation of OVs and 237 individuals for the non-use values. The results in Chang et al. (2012) were based on 1,000 individuals for each of the sub-studies. Both studies found that the OV represented slightly more than half of the combined non-use value and OV. Moreover, the estimated value for high-speed rail was higher than conventional rail (Chang 2010), and the estimate for interregional buses was higher than the estimate for regional buses and metropolitan buses.

Johnson et al. (2013) included valuations of post offices as a comparison with valuations for rail services in the English countryside. Based on a sample of 223 individuals, they found that non-use values declined rapidly with distance to the service, as opposed to use-values that were more stable with respect to distance. As for OVs, the paper reported that rural services had substantially lower values than commuter-oriented services, indicating that potential accessibility matters. Also, they found smaller values compared to earlier studies, which they argued might depend on their rural study area in contrast to other papers using urban or suburban areas. They reported OVs between 13 and 28 Euros per person and year (in terms of the monetary value of 2014), which represented slightly more than a third of the combined OV and non-use values.

Chang et al. (2017) estimated individuals' non-use values (which they defined as OVs and values related to some form of altruism or existence) of expressways in South Korea using a similar approach to Chang (2010) and Chang et al. (2012). They found that the OV represented half of the combined OV and non-use values, and higher values for men than women, people with high income, and for business trip purposes.

Besides the mentioned studies, two non-peer-reviewed studies have also analyzed the OV. The first, by Wallis and Wignall (2012), studied a few different bus and rail services and found that the OV 
represented about half of the TEV. The study reported a range of OVs between 16 Euros per person and year (2014) for a rail service and 4 Euros per person and year for a bus service. They also concluded that the most influential factors for overall willingness to pay were the service quality in terms of frequency, reliability, travel time, fare and accessibility to facilities in a town center. Within communities, the factors with the most significant influence were the household size and income as well as the distance from the local center and the households' expected public transport use.

The second study, by Laird et al. (2013), found non-use value estimates of almost zero in a national household survey but produced an estimate of the OV of 42 Euros per year (2014 prices) to keep local bus service from cuts. Their estimate of non-use values was just about 1 Euro per year. They also conducted a case study among households in Leeds regarding evening buses, Sunday bus services and high-quality bus service. They found substantially lower OV for the high-quality bus service than the evening and Sunday buses. The evening and Sunday bus estimates were in line with the results from the national survey concerning OV.

Both Laird et al. (2009) and later papers discuss that context specifics might have an impact on the different estimates and direct comparisons are, therefore, distorted. Further differences between studies come from different definitions of OVs and non-use values (Chang et al., 2017; Laird et al., 2009), and whether the studies observe households or individuals (Laird et al., 2009).

\subsection{Reflections of the literature}

Before proceeding, we make some reflections based on the literature in sections 2.1 and 2.2. First, individuals that are certain of demanding or certain of not demanding a service have no $\mathrm{OV}$, whereas uncertain individuals have a positive OV. In other words, the consumer surplus captures the total willingness to pay of a frequent user of a service (e.g., daily commuter), and the OV increases when use is infrequent, and timing of demand is unknown. Second, higher quality of service (e.g., better comfort and higher frequency) implies higher OV. Third, more transport options that serve the same purposes mean lower OV for each specific one. People living in a dense city with plenty of public transport services and other transport options are likely to assign a lower OV to each of them, compared to a situation where a given optional service would stand alone.

\section{Accessibility and substitutability}

As mentioned in section 1, there are two limitations in the empirical literature on OV. Firstly, particular research purposes across studies may lead to ad-hoc categorization of the OV, leading to difficulties to compare estimates. For instance, one researcher may define OV as a non-use value because it is not derived from active use, whereas another defines it as a use-value because it is assumed to be derived from potential use. Secondly, previous studies have with few exceptions studied individual public transport services. That is, they have not taken into account how much accessibility the particular transport services provide relative to the total level of accessibility of specific locations. This makes it impossible to compare estimates of the OV across contexts, and thus of little help to policy. The purpose of this section is to propose a generalizable measure of $\mathrm{OV}$.

\subsection{Accessibility}

Infrastructure-based accessibility measures (such as the frequency of a transport service), which the previous literature build on, has advantages in terms of interpretability, but also shortcomings in the theo- 
retical foundations and it leaves several questions unanswered. A crucial question is to what activities a particular transport service provides access. In addition to infrastructure-based accessibility measures, Geurs and van Wee (2004) discuss accessibility measures based on location, person and utility. Yet another taxonomy of measures is distinguishing cumulative opportunities measures, gravity-based measures, and utility-based measures (Handy \& Niemeier, 1997). In the rest of this paper, we use the utilitybased measures as a framework for discussion. Utility models take the full choice set of an individual into consideration and assume that the individual maximizes his or her utility.

In this paper, we use the logsum measure, which is based on the consumer surplus as a measure of welfare (Ben-Akiva \& Lerman, 1985; Eliasson \& Mattsson, 2000). The general travel cost function can be expressed as:

Cost $_{i, j, k}^{m}=\rho_{1}^{m}$ travel time $_{i, j}^{m}+\rho_{2}^{m}$ travel cost $_{i, j}^{m}+\ln ($ destinaton attractiveness $)$

That is, the generalized travel cost for mode $m$ for a trip from destination $i$ to destination $j$ is the sum of the time that the trip takes, the cost of the trip and how attractive the destination is, for each trip purpose $\mathrm{k}$. The resulting logsum per mode is calculated by summing the cost (or disutility) over zones and trip purpose:

$L S_{i}^{m}=\sum_{k} P_{k} \ln \sum_{j} \exp \left(\operatorname{Cost}_{i, j, k}^{m}\right)$

Where P denotes the modal share with mode $\mathrm{k}$. The total logsum for zone $\mathrm{i}$ is then calculated by:

$L S_{i}^{m}=\ln \sum_{m} \exp \left(L S_{i}^{m}\right)$

\subsection{Substitutability}

We have established a generalized accessibility measure and move on to how this can be related to the OV. Of course, one might ask whether the logsum is not already capturing the OV since all possible trips included add to the score, regardless if they are made or not. The answer is that it is not including the $\mathrm{OV}$, because the logsum is calibrated on past travel behavior, and there is no uncertainty connected to trips that are already made. Thus, we need an additional measure to account for uncertainty about individuals' future travel wants, which is why we use substitutability. Substitutability is defined as "the extent to which an initially preferred travel alternative can be substituted by other initially less preferred alternatives" (van Wee et al., 2019, p. 1).

The term substitutability stems from the economic concept of substitutes, such as the pear as a possible substitute for an apple. In the accessibility context we think of this in terms of transport modes and destinations; how well does mode $\mathrm{A}$ substitute for mode $\mathrm{B}$, or how well does destination $\mathrm{C}$ substitute for $\mathrm{D}$ ? As mentioned above, the $\mathrm{OV}$ is understood as the value of optional future use of a good or service. In line with Laird et al. (2009), we argue that transport is unique in the sense that it serves as an input to many other activities. From this follows that there might be a value of substitute transport alternatives in general. That is, we hypothesize that individuals could desire a substitute transport alternative even if there is no currently known final consumption want. What we need to do now is to concretize the link between OV and substitutability.

In this paper, we deviate from the original idea of substitutability in the sense that we only measure 
the substitutability between transport modes, not between destinations. We thus define substitutability as follows:

$S=\frac{\sum m P(Y=m) L S^{Y=m}}{L S}$

Where LSY=m comes from Equation 3 and denotes the "foregone logsum" for mode m, i.e., the logsum of zone i if mode $m$ was excluded. The substitutability score ranges from almost 1 , where all modes are equally important, to 0 , where one mode makes up all the accessibility. Substitutability is thus interpreted as how "robust" the accessibility is, i.e., to what degree it is made up of one or several modes.

If individuals value substitutability, they place a value on having several modes available, in contrast to the value of accessibility which is the value of the opportunities the individual can reach. We argue that the value individuals place on having several modes available is the OV of these modes. An estimate of substitutability thus reflects the total OV of all modes.

\section{$4 \quad$ Data and empirical model}

\subsection{Data}

Since not only accessibility to work is of interest when choosing where to live, we use accessibility for all trip types in this study. The accessibility (logsum) measured used in this study (see Equation 1) is calculated from Swedish national transport model SAMPERS (see Beser \& Algers, 2002, for a description of the model system). In short, SAMPERS is a system of models including a demand model and a route choice model. The calculations are made on over 10,000 small areas across Sweden, with input data on population and travel habits.

The model first estimates the demand for all types of trips ${ }^{1}$ to different kinds of individuals. It then estimates which destination the individuals choose, then which modes they choose. ${ }^{2}$ In the final step of the model, it determines which route the individuals choose based on the generalized cost of the trips. The model then iterates until it reaches equilibrium. At this stage, the model has information on route choice and costs for different types of trips, modes and individuals, and since the model is probabilistic, all destinations. The model then aggregates this information to the zone level using the average individual of each zone to yield the generalized cost of travel for each mode-destination combination. These costs are then used in Equation 2 to calculate the logsum.

Figure 1 shows the accessibility score in the study region (Skåne in the south of Sweden), based on these small geographical areas. We see that the west, being more populous, have better accessibility, especially the larger towns Malmö, Helsingborg and Lund. As described above, the substitutability score (Equation 2) is based on the same data source. In this paper, we have transformed substitutability into an index ranging from 0 (lowest) to 100 (highest). The substitutability scores of zones in Skåne are presented in Figure 2. The figures reveal that substitutability is more closely tied to urban areas and public transport services than accessibility which is more closely tied to population centers.

\footnotetext{
${ }^{1}$ The trip types included in the calculation are work, business trips and other trips.

${ }^{2}$ The modes included in the calculation are car, public transport, walk and bike.
} 


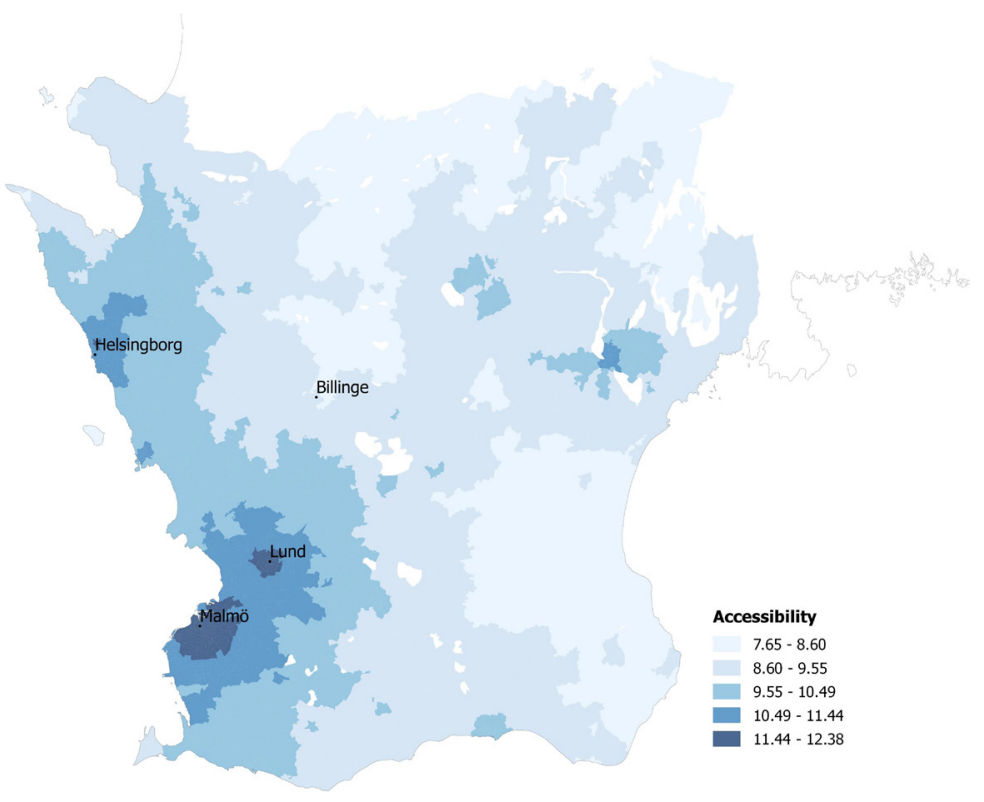

Figure 1. Logsum accessibility for all modes, trip purposes and destinations in the Skåne region (Sweden), calculated using Equation 3. The three major towns, Malmö, Helsingborg and Lund, are highlighted, as wells as a small community, Billinge, for comparative purposes in section 5.1.

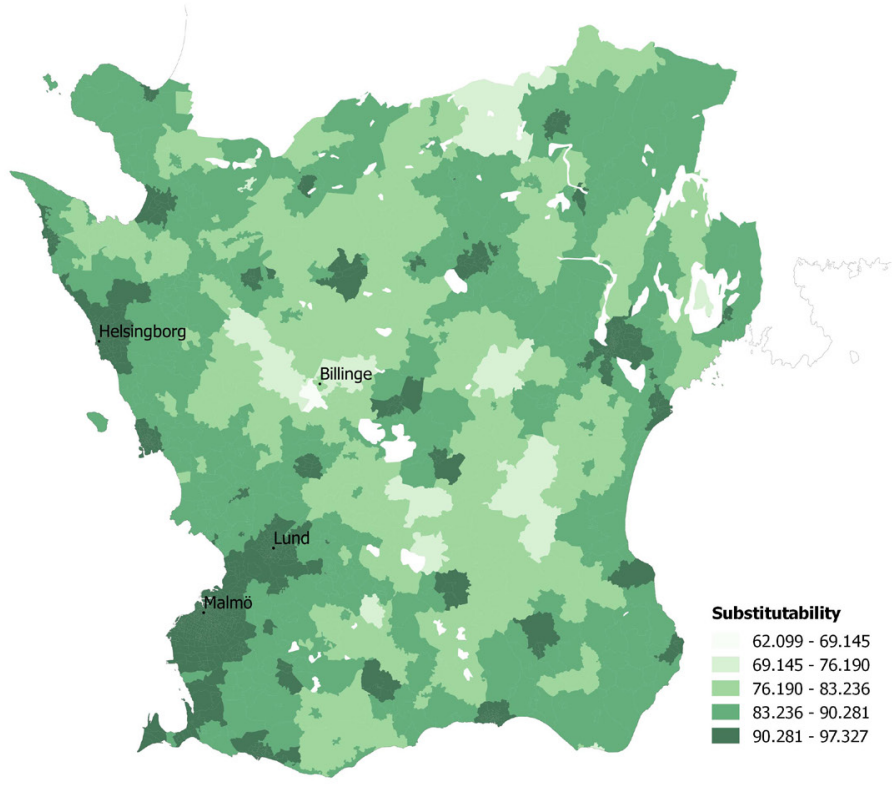

Figure 2. Substitutability of modes of transport in the Skåne region (Sweden), calculated using Equation 4. The three major towns, Malmö, Helsingborg and Lund, are highlighted, as wells as a small community, Billinge, for comparative purposes in section 5.1 .

The real estate data (presented in Table 2) we use covers transactions of both single-family homes and apartments in Skåne, the southernmost region of Sweden, for the years 2013 and 2014. This period corresponds to the latest available accessibility estimates from the SAMPERS model. Descriptive statistics of the data are presented in Table 2. Over these two years, some 20,000 transactions occurred. About 
10,000 of these were apartments and about 10,000 single-family homes. Skåne is a relatively diverse region, consisting of rural areas, as well as larger cities (among others Malmö, the third-largest city in Sweden, and Lund, one of the largest university towns). This diversity is visible in the variation in prices, which Table 2 displays. The average price of an apartment is 1.2 million Swedish kronor (SEK), and the average price of a single-family home is around 2.2 million SEK. Both apartments and single-family homes have large standard deviations.

Apartments are, on average, smaller than single-family homes, both measured as disposable living area and number of rooms. Apartments, however, have both higher accessibility and higher substitutability than single-family homes, which is consistent with theories on land-use. In more central locations, i.e., where accessibility is high, land values will be higher. High land values imply a greater degree of land exploitation, i.e., high-rise buildings. Furthermore, high rise buildings mean greater population density.

Table 2. Descriptive statistics for the two subsamples, apartments and single-family homes

\begin{tabular}{lcccc}
\hline & \multicolumn{2}{c}{ Apartments } & \multicolumn{2}{c}{ Single-family homes } \\
\hline Variable & Mean & St. dev & Mean & St. dev \\
\hline Price (SEK) & $1,252,866$ & 843,423 & $2,189,218$ & $1,538,762$ \\
& Unit-specific indicators & & & \\
\hline Living area $\left(\mathrm{m}^{2}\right)$ & 71.19 & 25.44 & 132.4 & 42.78 \\
Number of rooms & 2,56 & 0.99 & 5.06 & 1.42 \\
Age (years) & 53.14 & 175.1 & 57.89 & 67.5 \\
Monthly fee (SEK) & $3,909.9$ & $1,382.6$ & - & - \\
Plot area (m ${ }^{2}$ ) & - & - & $1,378.5$ & $2,621.2$ \\
& Accessibility indicators & & & 0.9 \\
\hline Accessibility & 11.39 & 0.84 & 9.89 & 4.36 \\
Substitutability & 95.19 & 2.27 & 89.42 & \\
\hline Number of observations & \multicolumn{1}{c}{10,133} & & & \\
\hline
\end{tabular}

\subsection{Hedonic model}

We test if we can observe an OV (indicated by substitutability as in Equation 2) for transport services on an aggregate level by hedonic modelling using transactions of single-family homes and apartments in Skåne. Measuring the value of accessibility is commonly done by estimating hedonic models. The hedonic model was first introduced by Rosen (1974) as a proposed framework to observe the implicit prices of intangible goods, such as accessibility. The real estate market provides a good empirical ground for hedonic modelling. Real estate can be seen as a bundle of different attributes and commodities, including accessibility. Since both accessibility and prices of real estate vary, statistical methods allow us to estimate the implicit price of accessibility, through observing real estate prices. Debrezion et al. (2007) provide a state-of-the-art review, including 55 studies to estimate the impact of railway stations on real estate prices. All studies included applies a hedonic modelling approach. In this paper, we will estimate a model given by Equation 3:

$\log \left(\right.$ price $\left._{i, j}\right)=\alpha * A_{j}+\beta * S_{j}+\delta * X_{i}+\varepsilon$ 
That is, we regress the log of the price of house $i$ in zone $j$ on accessibility $(A)$ and substitutability $(S)$ of transportation modes in zone $j$ (see Equations 1 and 2 for accessibility and substitutability, respectively), and $X$, which is a matrix of property attributes of house $i . \alpha, \beta$ and $\delta$ are the parameters to be estimated. $\varepsilon$ is assumed to be a random error term with zero mean and constant variance. If individuals attach a value to having several modes available (OV), the substitutability parameter, $\beta$, will have a positive sign. We expect that better accessibility and substitutability are positively associated with real estate prices. Thus, we hypothesize that both $\alpha$ and $\beta$ are positive.

\section{$5 \quad$ Results and discussion}

\subsection{Results}

We estimate six separate models (I through VI): three models explaining the variation in price for apartments (models I-III, Table 3), and three models explaining the variation in the price of single-family homes (models IV-VI, Table 4). In models I and IV, we are estimating unit-specific variables and the $\log$ sum measure of accessibility (summarized in Table 2). In models II and V, we have replaced accessibility with substitutability. In models III and VI, we are estimating models using both accessibility and substitutability. Both time-fixed and location-fixed effects are included in the models but left out of the display in Table 3 and Table 4.

Table 3. Regression results for apartments. Dependent variable: $\log$ of the transaction price

\begin{tabular}{|c|c|c|c|c|c|c|}
\hline \multirow[b]{3}{*}{ Variable } & \multicolumn{6}{|c|}{ Apartments } \\
\hline & \multicolumn{2}{|c|}{ Model I } & \multicolumn{2}{|c|}{ Model II } & \multicolumn{2}{|c|}{ Model III } \\
\hline & Coefficient & p-value & Coefficient & p-value & Coefficient & p-value \\
\hline Living area & 0.022 & 0.000 & 0.022 & 0.000 & 0.022 & 0.000 \\
\hline Number of rooms & 0.164 & 0.000 & 0.161 & 0.000 & 0.163 & 0.000 \\
\hline $\begin{array}{l}\text { Living area*Number of } \\
\text { rooms }\end{array}$ & -0.002 & 0.000 & -0.002 & 0.000 & -0.002 & 0.000 \\
\hline $\begin{array}{l}\text { Monthly fee (1000 } \\
\text { SEK) }\end{array}$ & -0.112 & 0.000 & -0.123 & 0.000 & -0.112 & 0.000 \\
\hline Floor & 0.011 & 0.000 & 0.011 & 0.000 & 0.011 & 0.000 \\
\hline \multicolumn{7}{|l|}{ Plot area } \\
\hline Age & -0.000 & 0.010 & -0.000 & 0.016 & -0.000 & 0.009 \\
\hline $\mathrm{Age}^{\wedge} 2$ & 0.000 & 0.017 & -0.000 & 0.024 & 0.000 & 0.016 \\
\hline Accessibility & 0.239 & 0.000 & & & 0.161 & 0.000 \\
\hline Substitutability & & & 0.046 & 0.000 & 0.020 & 0.006 \\
\hline Intercept & 10.430 & 0.000 & 8.814 & 0.000 & 9.410 & 0.000 \\
\hline Time dummies & \multicolumn{2}{|c|}{ Yes } & \multicolumn{2}{|c|}{ Yes } & \multicolumn{2}{|c|}{ Yes } \\
\hline Location dummies & \multicolumn{2}{|c|}{ Yes } & \multicolumn{2}{|c|}{ Yes } & \multicolumn{2}{|c|}{ Yes } \\
\hline adj. $R^{\wedge} 2$ & \multicolumn{2}{|c|}{0.78} & \multicolumn{2}{|c|}{0.78} & \multicolumn{2}{|c|}{0.78} \\
\hline Number of observations & \multicolumn{2}{|c|}{10,133} & \multicolumn{2}{|c|}{10,133} & \multicolumn{2}{|c|}{10,133} \\
\hline AIC & \multicolumn{2}{|c|}{3836.714} & \multicolumn{2}{|c|}{3849.649} & \multicolumn{2}{|c|}{3831.207} \\
\hline
\end{tabular}


Table 4. Regression results for single-family homes. Dependent variable: log of the transaction price

\begin{tabular}{|c|c|c|c|c|c|c|}
\hline \multirow[b]{3}{*}{ Variable } & \multicolumn{6}{|c|}{ Single-family } \\
\hline & \multicolumn{2}{|c|}{ Model IV } & \multicolumn{2}{|c|}{ Model V } & \multicolumn{2}{|c|}{ Model VI } \\
\hline & Coefficient & $\mathrm{p}$-value & Coefficient & $\mathrm{p}$-value & Coefficient & p-value \\
\hline Living area & 0.007 & 0.000 & 0.007 & 0.000 & 0.007 & 0.000 \\
\hline Number of rooms & 0.081 & 0.000 & 0.080 & 0.000 & 0.080 & 0.000 \\
\hline $\begin{array}{l}\text { Living area*Number of } \\
\text { rooms }\end{array}$ & 0.000 & 0.000 & -0.000 & 0.000 & 0.000 & 0.000 \\
\hline \multicolumn{7}{|l|}{$\begin{array}{l}\text { Monthly fee (1000 } \\
\text { SEK) }\end{array}$} \\
\hline \multicolumn{7}{|l|}{ Floor } \\
\hline Plot area & 0.000 & 0.000 & 0.000 & 0.000 & 0.000 & 0.000 \\
\hline Age & -0.003 & 0.000 & -0.003 & 0.000 & -0.003 & 0.000 \\
\hline $\mathrm{Age}^{\wedge} 2$ & 0.000 & 0.000 & 0.000 & 0.000 & 0.000 & 0.000 \\
\hline Accessibility & 0.282 & 0.000 & & & 0.153 & 0.000 \\
\hline Substitutability & & & 0.028 & 0.000 & 0.017 & 0.000 \\
\hline Intercept & 10.790 & 0.000 & 11.419 & 0.000 & 10.690 & 0.000 \\
\hline Time dummies & \multicolumn{2}{|c|}{ Yes } & \multicolumn{2}{|c|}{ Yes } & \multicolumn{2}{|c|}{ Yes } \\
\hline Location dummies & \multicolumn{2}{|c|}{ Yes } & \multicolumn{2}{|c|}{ Yes } & \multicolumn{2}{|c|}{ Yes } \\
\hline adj. $R \wedge 2$ & \multicolumn{2}{|c|}{0.77} & \multicolumn{2}{|c|}{0.77} & \multicolumn{2}{|c|}{0.77} \\
\hline Number of observations & \multicolumn{2}{|c|}{9,406} & \multicolumn{2}{|c|}{9,406} & \multicolumn{2}{|c|}{9,406} \\
\hline AIC & \multicolumn{2}{|c|}{5964.669} & \multicolumn{2}{|c|}{5954.510} & \multicolumn{2}{|c|}{5911.752} \\
\hline
\end{tabular}

In Table 3 and Table 4, we can see that the estimated coefficients for all variables are robust across all model specifications, carry expected signs and fall with reasonable magnitudes. All models also explain much of the variation in prices, around 77 percent. When it comes to the coefficients of interest, accessibility and substitutability, the signs are as expected. Accessibility has a positive impact on prices for both apartments and single-family homes.

When we include both accessibility and substitutability (models III and VI), the estimated coefficients for accessibility changes. This result is expected since the correlation between accessibility and substitutability is rather large and positive. Having high accessibility is partly due to more beneficial options in terms of transport alternatives. The effect of substitutability is positive and significant for both apartments and single-family homes, and likelihood tests reveal that the substitutability variables significantly improves the model fit for both apartments and single-family homes. The AIC values also show that the models including only accessibility are 6 percent (apartments) and 0 percent (single-family homes) as likely as the models including both accessibility and substitutability to minimize information loss.

The results show that higher substitutability between transport modes is a positively valued attribute. Hence, not only the accessibility but also how the accessibility is constructed matters for the value of a location. Importantly, it indicates that previous studies exploring the value of accessibility have captured the OV of the transport system as well. As our results show, the estimates of accessibility in models I and IV contain some of the value of substitutability, which we argue estimates OV, not only the value of accessibility itself.

It is somewhat difficult to interpret the magnitude of the parameters as the scale of the variables is non-intuitive. Nevertheless, the estimated accessibility parameters imply that a one-unit increase in 
accessibility is associated with a 16 and 15 percent increase in the price of apartments and single-family homes, respectively. The corresponding interpretations for the estimated substitutability parameters are 2 and 1.7 percent for apartments and single-family homes, respectively. Keep in mind that accessibility varies between approximately 7.5 and 12.5, while substitutability varies between 62 and 97 .

Still, it might be helpful with an example. In Figure 1 and Figure 2, accessibility and substitutability in the Skåne region and a few reference places are highlighted: the three largest cities, Malmö, Helsingborg and Lund, as well as the village of Billinge in Eslöv Municipality. Model VI predicts that a 5 room and 120 square meters single-family house in Lund built 1960 with an 800 square meters plot costs about SEK 6.9 million. This specific area in Lund has an accessibility score of 11.86 and a substitutability score of 96 . The same type of house in Billinge, with an accessibility score of 8.98 and a substitutability score of 79 costs about SEK 1.3 million. If the house in Billinge would have had the same substitutability score as the house in Lund, the model predicts a price of SEK 1.7 million. The price difference attributed to the substitutability difference is thus approximately SEK 400,000.

\subsection{Discussion}

Our empirical test of the OV reveals a positive association between property values and both substitutability and accessibility. Thus, we argue that the $\mathrm{OV}$ is not just a theoretical idea but is an attribute that helps to explain how people value a location. But how does it fit into our theory? We cannot decompose the estimate, but we discuss plausible reasons for our findings.

The revealed preferences for a variety of modes can be an indication that individuals or households try to adjust to uncertainty and the existence of rare events with potentially harmful consequences. Even though we do not know about the certainty of availability of each transport mode, people likely prefer locations where the transport system is more reliable, which is mirrored in a willingness to pay a premium for those locations. Another way to think about the uncertainty facing individuals is that they are hedging the possibility that preferences or life situations change. People move their nest rather infrequently, which makes it likely that they prefer a more diverse transport portfolio, everything else being equal.

We derive the interpretation that households try to adjust to uncertainty and the existence of rare events from Knight's (1921) idea that uncertain events are unmeasurable and unpredictable. In other words, real uncertainty implies that households have to cope with the existence of rare events; they cannot perform probabilistic calculations on known turnouts. Another plausible interpretation, however, of the same finding is that households value a variety in consumption, as pointed out by van Wee (2016). Regardless of the level of certainty about the future, people could prefer a location with more alternatives. Both interpretations can coexist, but we cannot know which one is dominant in particular situations since we cannot control for uncertainty.

\section{$6 \quad$ Conclusions and policy implications}

We have sought to give a conceptual contribution to the literature on OV in transport and tested the substitutability measure as an indicator of OV against data on real estate prices. Previous empirical studies on OV employ various forms of stated preference models to extract estimates of OV for specific services. A general conclusion from the literature is that OVs are context-dependent and that the highest valued services in terms of the OV seems to be high-quality rail. In contrast, the lowest valued services are low-quality buses (Laird et al., 2009).

Further, previous literature on this topic is somewhat fragmented about the definition of OV, re- 
sulting in inconsistent taxonomies of TEV. Besides, only two papers (Chang, 2010; Chang et al.,2012) take a step towards including an accessibility perspective. We argue that the valuation method must be generalized to compare OV across modes and contexts. As a starting point, we acknowledge that valuation has to relate to the marginal changes accessibility that a transport service provides and thus correspond to the consumer surplus calculation. But because the $\mathrm{OV}$ is not traceable in travel behavior, it can only be estimated indirectly, for instance, hedonically using housing prices.

In this paper, we have analyzed accessibility and the concept of substitutability (the composition of accessibility) with inspiration from van Wee, et al. (2019). In all, the main finding of this paper is that the substitutability estimate is positively associated with real estate prices. We argue that revealed preferences rather than stated preferences make it possible to generalize the valuation across contexts. Our contribution to the literature is that we have presented an easier and cheaper way of soliciting OV through the substitutability measure. This approach avoids some of the main problems with stated preference studies, such as strategic answers and cognitive stress.

The chief policy implication is that we have shown that the OV, as estimated by substitutability as a location attribute, is not only a theoretical idea but empirically tractable as well. We also open up for relatively easy addition to standard accessibility analyses that can be of interest to policy-makers. By adding substitutability as an attribute next to the change of the total accessibility in an ex-ante appraisal, policy-makers get a grip on whether an area might become dominated by one transport mode. As Laird et al. (2009) pointed out, the OV is context-dependent, meaning that we cannot transfer a specific value across contexts straightforwardly. With substitutability, we now have a generalizable measure of the source of OV that can be applied in ex-post policy evaluation and, until there are national guidelines on a specific monetary value, in ex-ante appraisal besides a CBA.

\section{Acknowledgments}

The research was made with financial support from K2-The Swedish knowledge centre for public transport. The authors gratefully acknowledge input and comments from Karin Brundell-Freij, Lena Winslott Hiselius, Sirje Pädam, Bert van Wee, and the two anonymous reviewers. The authors would also like to acknowledge the comments on a previous version of the paper presented at the ITEA conference in 2017 and at Thredbo 15 in 2017. 


\section{References}

Barbier, E. B. (1994). Valuing environmental functions: Tropical wetlands. Land Economics, 70(2), 155-173. https://doi.org/10.2307/3146319

Ben-Akiva, M., \& Lerman, S. R. (1985). Discrete choice analysis: Theory and application to travel demand. Cambridge, MA: MIT Press. Retrieved from https://mitpress.mit.edu/books/discrete-choice-analysis

Beser, M. \& Algers, S. (2002). SAMPERS - The new Swedish national travel demand forecasting tool. In L. Lundqvist \& L. G. Mattsson (Eds.), National transport models, advances in spatial science (pp.101-118). Berlin: Springer. https://doi.org/10.1007/978-3-662-04853-5

Boardman, A., Greenberg, D., Vining, A., \& Weimer, D. (2014). Cost-benefit analysis: Concepts and practice. London: Pearson.

Bohman, H., \& Nilsson, D. (2016). The impact of regional commuter trains on property values: Price segments and income. Journal of Transport Geography, 56,102-109. https://doi.org/10.1016/j.jtrangeo.2016.09.003

Carson, R. T., Flores, N. E., \& Mitchell, R. C. (2001). The theory and measurement of passive-use value. In I. Bateman \& K. G. Willis (Eds.), Valuing environmental preferences: Theory and practice of the contingent valuation method in the US, EU, and developing countries (pp. 97-130). Oxford, UK: Oxford University Press.

Chang, J. S. (2010). Estimation of option and non-use values for intercity passenger rail services. Journal of Transport Geography, 18(2), 259-265. https://doi.org/10.1016/j.jtrangeo.2009.06.009

Chang, J. S., Cho, S. Y., Lee, B. S., Kim, Y., \& Yun, S. K. (2012). A dichotomous choice survey for quantifying option and non-use values of bus services in Korea. Transportation, 39(1), 33-54. https://doi.org/10.1007/s11116-011-9326-0

Chang, J. S., Jung, D., Ross, C. L., \& Kim, J. (2017). Evaluating the non-use values of expressways. Transportmetrica A: Transport Science, 13(5), 449-466. https://doi.org/10.1080/23249935.2017.12 93751

Cicchetti, C. J., \& Myrick Freeman III, A. (1971). Option demand and consumer surplus: Further comment. The Quarterly Journal of Economics, 85(3), 528-539.

Debrezion, G., Pels, E., \& Rietveld, P. (2007). The impact of railway stations on residential and commercial property value: A meta-analysis. Journal of Real Estate Finance and Economics, 35(2),161180. https://doi.org/10.1007/s11146-007-9032-z

Eliasson, J., Kopsch, F., Mandell, S., \& Wilhelmsson, M. (2020). Transport mode and the value of accessibility - A potential Input for sustainable investment analysis. Sustainability, 12(5), 2143. https:// doi.org/10.3390/su12052143

Eliasson, J., \& Mattsson, L. G. (2000). A model for integrated analysis of household location and travel choices. Transportation Research Part A, 34(5), 375-394. https://doi.org/10.1016/S09658564(99)00038-5

Geurs, K, \& van Wee, B. (2004). Accessibility evaluation of land-use and transport strategies: Review and research directions. Journal of Transport Geography, 12(2), 127-140. https://doi.org/10.1016/j. jtrangeo.2003.10.005

Geurs, K., Haaijer, R., \& Van Wee, B. (2006). Option value of public transport: Methodology for measurement and case study for regional rail links in the Netherlands. Transport Reviews, 26(5), 613-643. https://doi.org/10.1080/01441640600655763

Handy, S. L., \& Niemeier, D. A. (1997). Measuring accessibility: An exploration of issues and alternatives. Environment and Planning A, 29(7), 1175-1194. https://doi.org/10.1068/a291175

Humphreys, M., \& Fowkes, A. S. (2006). The significance of indirect use and non-use values in trans- 
port appraisal. International Journal of Transport Economics, 33(1), 17-35. http://www.jstor.org/ stable/42747776

Johnson, D., Jackson, J., \& Nash, C. (2013). The wider value of rural rail provision. Transport Policy, 29, 126-135. https://doi.org/10.1016/j.tranpol.2013.04.007

Knight, F. H. (1921). Risk, uncertainty, and profit. Boston, MA: Hart, Schaffner \& Marx, Houghton Mifflin Co.

Krutilla, J. (1967). Conservation reconsidered. The American Economic Review, 57(4), 777-876.

Laird, J., Johnson, D., Corso, M., \& Tucta, I. (2013). Option values in bus networks. Paper presented at the Scottish Transport Applications and Research (STAR) Conference, April 17, Glasgow.

Laird, J., Geurs, K., \& Nash, C. (2009). Option and non-use values and rail project appraisal. Transport Policy, 16(4), 173-182. https://doi.org/10.1016/j.tranpol.2009.05.002

Lindsay, C. M. (1969). Option demand and consumer's surplus. The Quarterly Journal of Economics, 83(2), 344-346.

Long, M. F. (1967). Collective-consumption services of individual-consumption goods: Comment. The Quarterly Journal of Economics, 81(2), 351-352.

Mohammad, S. I., Graham, D. J., Melo, P. C., \& Anderson, R. J. (2013). A meta-analysis of the impact of rail projects on land and property values. Transportation Research Part A: Policy and Practice, 50, 158-170. https://doi.org/10.1016/j.tra.2013.01.013

Parry, I. W. H., \& Small, K. A. (2009). Should urban transit subsidies be reduced? The American Economic Review, 99(3), 700-724.

Rosen, S. (1974). Hedonic prices and implicit markets: Product differentiation in pure competition. Journal of Political Economy 82(1), 34-55.

Stanley, J., \& Levinson, D. (2016). Workshop 3 report: Sustainable funding sources and related cost benefit measurements. Research in Transportation Economics, 59,143-150. https://doi.org/10.1016/j. retrec.2016.10.004

Taleb, N. N. (2010). The black swan: The impact of the highly improbable. London: Penguin Books.

van Wee, B. (2016). Accessible accessibility research challenges. Journal of Transport Geography, 51, 9-16. https://doi.org/10.1016/j.jtrangeo.2015.10.018

van Wee, B., van Cranenburgh, S., \& Maat, K. (2019). Substitutability as a spatial concept to evaluate travel alternatives. Journal of Transport Geography, 79. https://doi.org/10.1016/j.jtrangeo.2019.102469

Wallis, I., \& Wignall, D. (2012). The benefits of public transport - option values and non-use values (Research report 471). Wellington, NZ: NZ Transport Agency.

Weisbrod, B. A. (1964). Collective-consumption services of individual-consumption goods. The Quarterly Journal of Economics, 78(3), 471-477. https://doi.org/10.1007/s13398-014-0173-7.2 